\title{
Study on Characteristics of Ultrasound Amplitude for the Concrete under Stress
}

\author{
Ling Zhang ${ }^{1,2, a^{*}}$, Lili Gao ${ }^{2, b}$ and Chunling Yan ${ }^{2, c}$ \\ ${ }^{1}$ School of Civil Engineering and Architecture, Wuhan University of Technology, China; \\ ${ }^{2}$ School of Civil and Architectural Engineering, Anyang Institute of Technology, China \\ accuiyanyan2003@126.com, byclhengyang@163.com, cyanchunling2003@163.com
}

\begin{abstract}
Keywords: ultrasound examination; concrete; compressed state; the amplitude
Abstract. Cube concrete samples $(150 \times 150 \times 150 \mathrm{~mm})$ of five ages (7, 14, 21, 28 and 35d) under different stress conducted the ultrasound examination by non-metallic detector and universal testing machine. The results show that the relationship curve of the stress and the ultrasound amplitude can be divided into four stages, the smooth linear stage, the linear deceleration stage, the like smooth lines stage and the attenuation damage stage from the loading beginning to the ultimate strength for concrete samples of the same age and different configuring strength. Ultrasound amplitude of concrete samples get smaller with the increase of the stress; when the concrete samples damage, the smallest sound velocity is derived. According to measured ultrasound amplitude under different stress and different configuring strength of the concrete, fitting function is used by Boltzmann, and the correlation coefficient was calculated to obtain concrete development model under different loading conditions and different ages.
\end{abstract}

\section{Introduction}

In recent years, many experts and scholars at home and abroad have made a lot of research on nondestructive examination to concrete aspects and have obtained greatly valuable results[1-3]. Ultrasonic wave, a means of non-destructive examination of the concrete, has been widely applied from the late 1940s. In the 1960's, Romanian Professor Facaoaru tested concrete strength by sound velocity combined rebound method. 20 years later, American Sansalone and Carino used the impacting echo method for nondestructive test to the concrete[4]. The principle is that ultrasonic velocity depends on the parameters of the density and elastic constant[5]. Therefore, the relevant information of concrete strength and quality is obtained by detecting velocity rate of the ultrasound[6]. At present, the study on ultrasonic examination of the concrete mainly considers these factors, such as different sizes, different intensity levels, aggregate types, moisture content and other factors. Nakahata et al[7] had studied three-dimensional numerical modeling of ultrasonic wave propagation in concrete and observed that amplitude of the transmitted signal was sensitive to the allocation pattern of the aggregates. Zhang et at [8] studied the characteristics of ultrasonic velocity for the concrete under stress and obtained the relationship curve of the stress and the ultrasonic velocity. Professor Larcher[9] also carried out a series of tests to study a viscoelastic mechanical characterization of asphalt materials by ultrasonic measurements, and finally drew the conclusion that the ultrasonic test results agreed with results obtained by complex modulus test.

These ideas and methods have certain significance for the research on propagation characteristics of the ultrasound for the concrete under the stress. However, the results may be not the same for different concrete samples, different ages and different loads and few people research the change of the amplitude for the concrete under the stress. The paper discusses the law of the ultrasound amplitude on concrete samples under the compression through the test, considering the age, the loading and concrete configuration strength. 


\section{Experimental Design}

Test Instrument. The production of non metal ultrasonic detector (Model: ZBL-U510) made in Beijing Zhibo technology Co., Ltd. is shown in Fig. 1. Hydraulic universal testing machine (Model: WE-2000) produced by Jinan Shijin Co., Ltd is shown in Fig. 2.
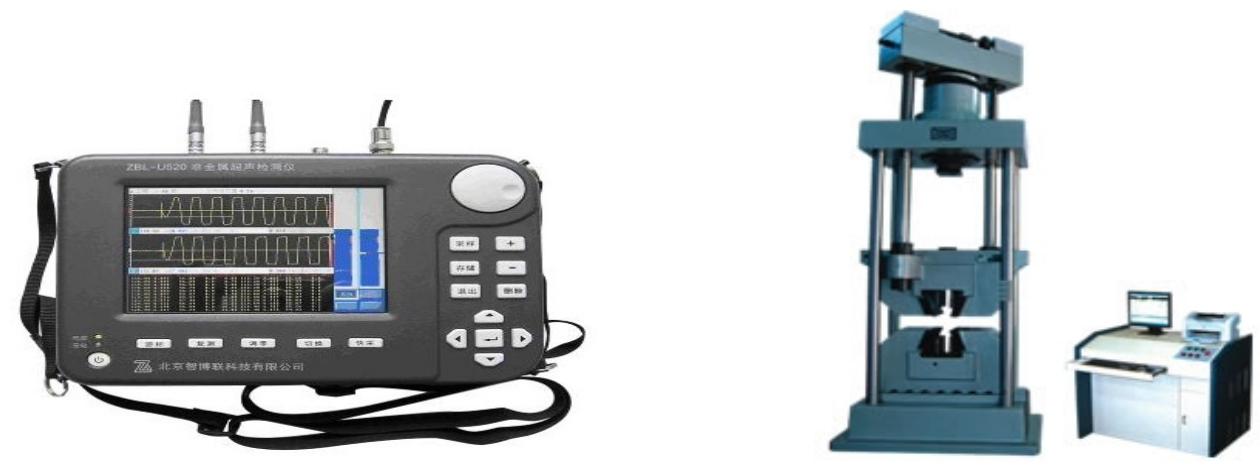

Fig.1 ZBL-U510 ultrasonic detector Fig. 2 WE-2000 hydraulic universal testing machine

Concrete Sample Preparation. Cube concrete samples are made from P. O. 42.5R ordinary Portland cement, medium sand, coarse aggregate with the size of 5-20 mm of continuous grading macadam, and tap water. The maintenance of the concrete samples are arranged on the standard curing room.

Test Methods. Cube concretes $(150 \times 150 \times 150 \mathrm{~mm})$ of five ages $(7 \mathrm{~d}, 14 \mathrm{~d}, 21 \mathrm{~d}, 28 \mathrm{~d}, 35 \mathrm{~d})$ were fabricated and concrete samples $(\mathrm{C} 20, \mathrm{C} 30, \mathrm{C} 35, \mathrm{C} 40$ and C45) of every age were also fabricated. Measuring points were arranged in the midpoint of the test simple and the detection direction is perpendicular to the direction of the force, as shown in Fig. 3. The detection time is recorded each loading $10 \mathrm{kN}$ until the test sample is destroyed in the process; the ultrasonic amplitude is obtained.

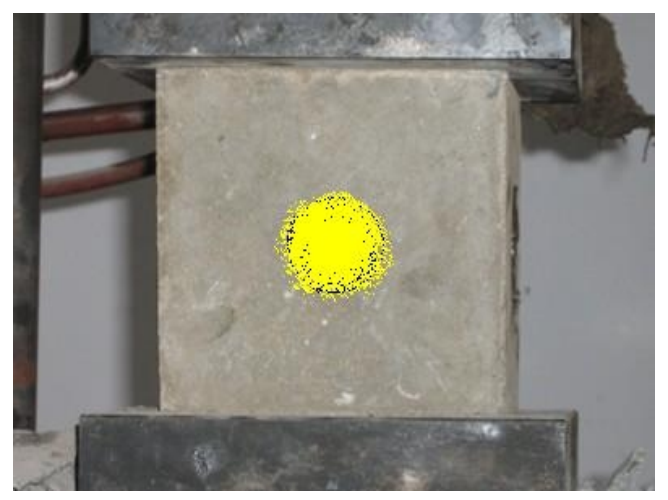

Fig.3 Loading and arrangement of detecting points

\section{Analysis of Test Results}

The impact of stress to the ultrasonic amplitude. Fig. 4 shows the relationship of loading stress and the ultrasonic amplitude for the same age and the same concrete preparation strength; the overall trend demonstrates that the ultrasonic amplitude is gradually smaller with the increase of loading stress. When the concrete block is destroyed, the value of ultrasonic amplitude is the smallest. The results display that the relationship curve can be divided into four stages: the smooth linear stage-the change of the ultrasonic amplitude is very small in the beginning; the linear deceleration stage-the ultrasonic amplitude decreases rapidly when the loading reaches a certain stress value; the like smooth lines stage-with the increase of the stress, the amplitude is approximate linear change when it decreases to a certain value; the attenuation damage stage-the curve steepens again and the ultrasonic amplitude sharply decline until the loading stress gradually approaches the limit of concrete. 


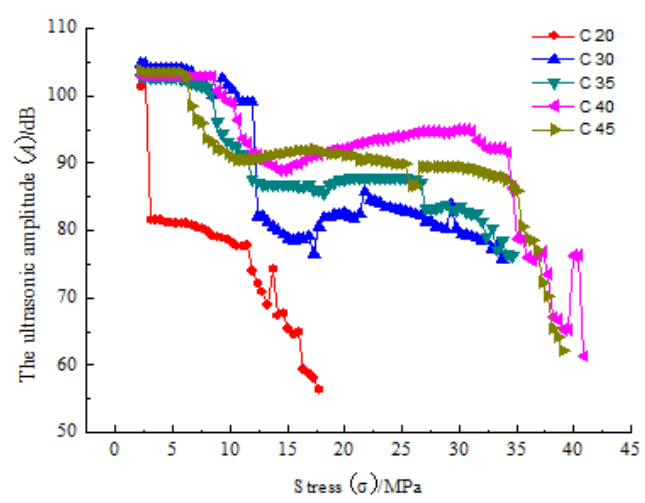

(a) Relationship of stress and ultrasonic amplitude (7d)

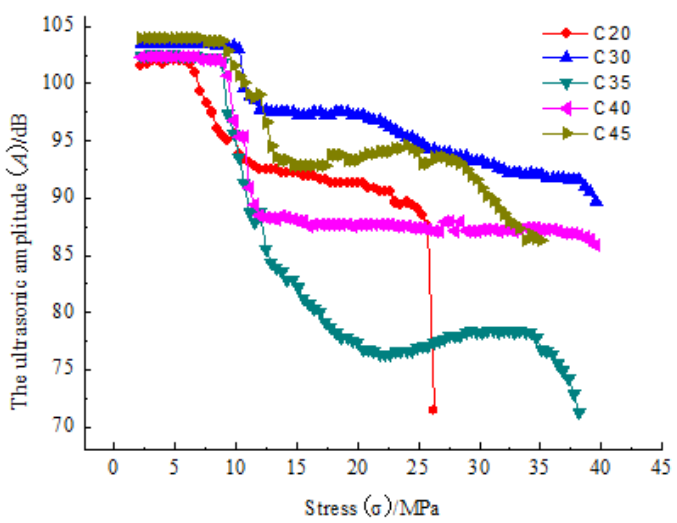

(b) Relationship of stress and ultrasonic amplitude (14d)

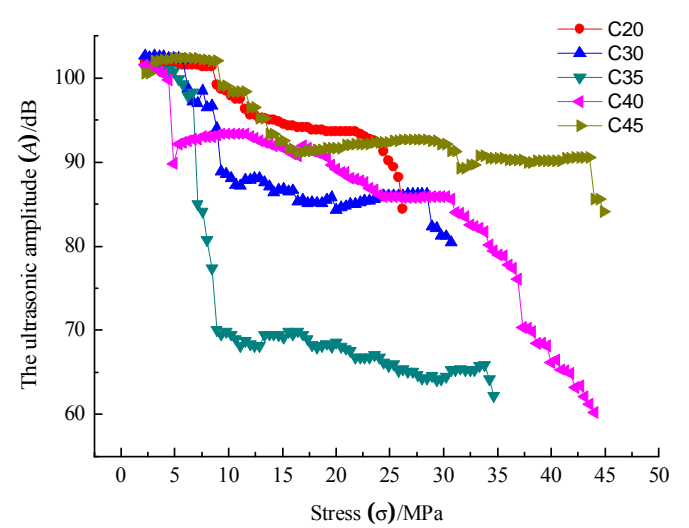

(c) Relationship of stress and ultrasonic amplitude (21d)

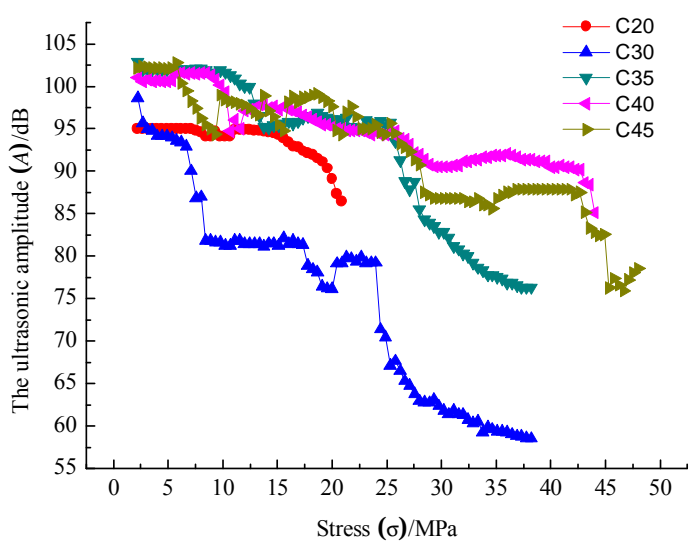

(d) Relationship of stress and ultrasonic amplitude (28d)

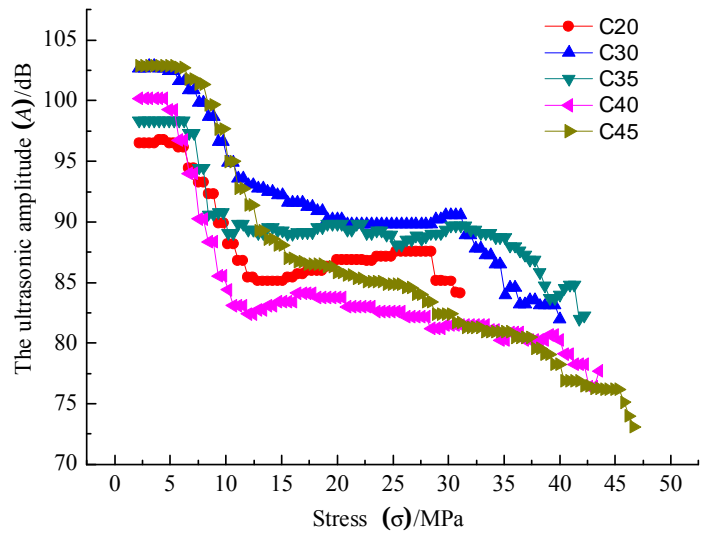

(e) Relationship of stress and ultrasonic amplitude (35d)

Fig.4 Relationship of stress and ultrasonic amplitude for different ages

Relationship of Stress and Ultrasonic Amplitude. According to the amplitude of the ultrasonic wave in the concrete under different stress and different configuration strength, the fitting of Boltzmann (Boltzmann) function is adopted.

$$
y=A_{2}+\left(A_{1}-A_{2}\right) /\left(1+\exp \frac{x-x_{0}}{d x}\right)
$$


Table 1 Regression results between ultrasonic amplitude and loading stress for the concrete in different ages

\begin{tabular}{|c|c|c|c|c|c|c|}
\hline \multirow{2}{*}{ Ages } & \multirow{2}{*}{$\begin{array}{c}\text { Strength } \\
\text { design }\end{array}$} & \multicolumn{4}{|c|}{ Fitting coefficient } & \multirow{2}{*}{$\frac{\text { Correlation coefficient }}{R^{2}}$} \\
\hline & & $A_{1}$ & $A_{2}$ & $X_{0}$ & $d x$ & \\
\hline \multirow{5}{*}{$7 \mathrm{~d}$} & $\mathrm{C} 20$ & 102.681 & -825.963 & 56.868 & 13.143 & 0.891 \\
\hline & C30 & 102.522 & 80.956 & 12.165 & 0.102 & 0.957 \\
\hline & $\mathrm{C} 35$ & 103.295 & 85.345 & 9.889 & 1.395 & 0.867 \\
\hline & $\mathrm{C} 40$ & 103.219 & 91.815 & 10.357 & 0.961 & 0.853 \\
\hline & C45 & 104.389 & 89.177 & 7.445 & 1.065 & 0.905 \\
\hline \multirow{5}{*}{$14 d$} & $\mathrm{C} 20$ & 103.325 & 90.588 & 8.598 & 2.113 & 0.958 \\
\hline & C30 & 137.724 & 85.679 & -10.008 & 22.522 & 0.951 \\
\hline & C35 & 103.728 & 77.172 & 11.431 & 1.865 & 0.980 \\
\hline & $\mathrm{C} 40$ & 102.430 & 87.424 & 10.425 & 0.679 & 0.993 \\
\hline & $\mathrm{C} 45$ & 104.110 & 91.948 & 11.732 & 1.260 & 0.864 \\
\hline \multirow{5}{*}{$21 d$} & $\mathrm{C} 20$ & 102.352 & 93.012 & 10.855 & 2.247 & 0.965 \\
\hline & C30 & 103.530 & 85.193 & 8.410 & 1.563 & 0.950 \\
\hline & C35 & 101.549 & 66.883 & 7.616 & 0.748 & 0.976 \\
\hline & $\mathrm{C} 40$ & 97.096 & -188.597 & 97.781 & 13.650 & 0.954 \\
\hline & $\mathrm{C} 45$ & 102.183 & 90.884 & 12.109 & 1.615 & 0.904 \\
\hline \multirow{5}{*}{$28 \mathrm{~d}$} & $\mathrm{C} 20$ & 94.842 & -190.653 & 29.389 & 2.433 & 0.974 \\
\hline & $\mathrm{C} 30$ & 96.152 & 79.376 & 7.563 & 1.155 & 0.879 \\
\hline & C35 & 101.422 & 69.371 & 29.209 & 5.517 & 0.958 \\
\hline & $\mathrm{C} 40$ & 106.428 & 88.240 & 14.675 & 11.863 & 0.916 \\
\hline & $\mathrm{C} 45$ & 99.274 & 86.289 & 25.746 & 2.399 & 0.929 \\
\hline \multirow{5}{*}{$35 \mathrm{~d}$} & $\mathrm{C} 20$ & 96.546 & 86.191 & 8.818 & 1.022 & 0.952 \\
\hline & $\mathrm{C} 30$ & 106.077 & 89.133 & 9.026 & 3.603 & 0.953 \\
\hline & $\mathrm{C} 35$ & 98.506 & 89.056 & 7.954 & 0.618 & 0.962 \\
\hline & $\mathrm{C} 40$ & 101.426 & 81.636 & 7.624 & 1.450 & 0.929 \\
\hline & $\mathrm{C} 45$ & 101.722 & 73.216 & -63.013 & 19.590 & 0.962 \\
\hline
\end{tabular}

\section{Summary}

(1) The relationship curve between the stress and the ultrasound amplitude can be divided into four stages, the smooth linear stage, the linear deceleration stage, the like smooth lines stage and the attenuation damage stage from the beginning loading to the ultimate strength.

(2) The overall trend demonstrates the ultrasonic amplitude is gradually smaller with the increase of loading stress.

(3) During the loading process, the curve point mutation occurs three times, the first time is the turning point for the smooth linear stage and the linear deceleration stage; the second time is the turning point for the smooth linear stage and the like smooth lines stage; the last time is the like smooth lines stage and the attenuation damage stage.

(4) According to the ultrasonic amplitude in different stress and different concrete strength, Boltzmann regression equation is obtained and the correlation coefficient is calculated. Further, any correlation coefficient is greater than 0.8 , which indicates that fitting equations are significant correlation and fitting results are credible.If you follow the "checklist" your paper will conform to the requirements of the publisher and facilitate a problem-free publication process.

\section{References:}

[1] Aggelis, G. Dimitrios. Wave propagation through engineering materials: assessment and monitoring of structures through non-destructive techniques, Materials and Structures. 46 (2013) 519-532. 
[2] Seher Matthias, In Chi-Won, Kim Jin-Yeon, Numerical and Experimental Study of Crack Depth Measurement in Concrete Using Diffuse Ultrasound, Journal of Nondestructive Evaluation. 32 (2013) 81-92.

[3] Petro John T Jr, Kim Jubum, Detection of delamination in concrete using ultrasonic pulse velocity test, Construction and Building Materials. 26 (2012) 574-582.

[4] Enhai Hao, Jie Liu, Zhonghai Wang, The study on relation between crush intensity and elastic modulus and velocity of ultrasonic sound for concrete, Journal of Tianjin University. 35 (2002) 380-383.

[5] H. 1. Wang, Y. P. Song, Ultrasonic pulses behavior in various-size concrete specimens under compression, Journal of Dalian University of Technology. 47 (2007) 90-94..

[6] Q. H. Dong, Newly developments of ultrasonic and acoustic wave testing of concrete, Concrete, $11(2005)$ 33-35.

[7] K. Nakahata, G. Wawanura, T. Yano, Three-dimensional numerical modeling of ultrasonic wave propagation in concrete and its experimental validation, Construction and Building Materials. 78 (2015) 217-223.

[8] L. Zhang, C. L. Yan. Study on Characteristics of Ultrasonic Velocity for the Concrete under Stress, Applied Mechanics and Materials. 438-439 (2013) 220-223.

[9] N. Larcher, M. Takarli, N. Angellier, Towards a viscoelastic mechanical characterization of asphalt materials by ultrasonic measurements, Materials and Structures, 48(2015) 1377-1388. 